\title{
ARTICLE
}

\section{Your patient and weight-loss surgery}

\author{
Tom Stevens, Samantha Spavin, Samantha Scholtz \& Lisa McClelland
}

Tom Stevens is a consultant general adult and liaison psychiatrist at South London and Maudsley NHS Foundation Trust, and an honorary consultant psychiatrist at St George's Hospital, London. Samantha Spavin is a consultant psychiatrist in general adult psychiatry with South West London and St George's Mental Health NHS Trust. Samantha Scholtz is an honorary consultant psychiatrist at the Imperial Weight Centre, Imperial College Healthcare NHS Trust, London. Lisa McClelland is a consultant general adult psychiatrist at Devon Partnership NHS Trust, UK. Correspondence Dr Tom Stevens. Lambeth Hospital, 108 Landor Road, London SW9 9NT, UK. Email: tom.stevens@slam.nhs.uk

\section{SUMMARY}

Obesity is common in patients with mental illness. Weight-loss surgery, known as bariatric surgery, is becoming a familiar intervention for treating people who are morbidly obese and for whom other weight-reduction methods have failed. This article offers guidance for mental health professionals on the assessment and management of patients with mental illness undergoing such treatment. Assessment is of the patient's suitability for surgery, taking into account their mental health diagnosis, expectations, knowledge and insight into the psychological impact of surgery, and ability to address and cope with lifestyle changes before and after surgery. The patient's capacity and ability to cooperate and engage with services are also assessed. Potential risks and complications of bariatric surgery and how the weight-loss procedures may affect patients' mental health and management of their medication are addressed.

\section{DECLARATION OF INTEREST}

None.

Obesity is a serious public health problem and a particular challenge in people with mental health disorders (Devlin 2000). Bariatrics is the branch of medicine that offers treatment of obesity, and bariatric surgery is an increasingly common intervention for morbid obesity. It is typically requested by the primary care team. Before an individual is considered for surgery, the National Institute for Health and Clinical Excellence (NICE) expects the patient to have engaged with a multicomponent programme of lifestyle change that has been individually tailored by a competent healthcare professional (National Collaborating Centre for Primary Care 2006). This should have incorporated a behavioural intervention to increase levels of physical activity and improve eating behaviour and quality of diet. In many cases, drug treatment with the lipase inhibitor orlistat will have been tried, although failure to respond to drug treatment is not a requirement for surgery. NICE has recommended that surgery be considered for all those with a body mass index (BMI) greater than $40 \mathrm{~kg} / \mathrm{m}^{2}$ who have failed to respond to other interventions and for those with a BMI greater than $35 \mathrm{~kg} / \mathrm{m}^{2}$ with obesity-related comorbid illnesses. Clinical studies have reported rates of obesity in patients with schizophrenia and bipolar affective disorder of up to 60\% (McElroy 2009). Those with severe mental illness have increased rates of medical conditions connected with obesity, including diabetes, cardiovascular disease and metabolic syndrome (Sims 1987).

Weight loss surgery has been shown in the USA to reduce overall mortality by $40 \%$ over a mean 7 years. The same study showed that there was a $56 \%$ reduction in death from coronary artery disease, a $92 \%$ reduction for those with diabetes and a $60 \%$ reduction in death from cancer after gastric bypass surgery (Adams 2007).

Patients can access information on surgery through a range of online resources, such as the British Obesity Surgery Patient Association (www. bospa.org).

\section{Psychological morbidity among those seeking bariatric surgery}

Early studies failed to identify obesity as a risk factor for psychiatric illness (Friedman 1995), and more recent community population surveys have also cast doubt on the relevance of obesity to psychiatric illness. Researchers have suggested that comorbid physical illness explains any variance identified (John 2005). Indeed, Stunkard \& Wadden (2000) argued that 'although there have been many reports of emotional disturbance amongst the obese, numerous careful studies have shown little difference in psychopathology as compared with non-obese people in the general population'. These findings contrast with an emerging evidence base identifying high rates of depression, binge eating and other psychiatric disorders in patients seeking dietary or surgical treatment. Rates of lifetime psychiatric disorder have been identified to be as high as 66\% among bariatric surgery candidates in the USA (Kalarchian 2007). Herpertz and colleagues (2004) estimated that rates of Axis I disorders among those waiting for surgery vary from 27.3 to $41.8 \%$, with mood disorder being the most prevalent.

Given these high rates of psychiatric comorbidity in patients presenting for surgery, and the potential for postoperative psychological complications, NICE recommends that a multidisciplinary team with psychiatric or psychological expertise carefully selects candidates for bariatric surgery (Box 1). Potential patients should undergo a 
BOX 1 NICE criteria for surgery

- The person's BMl is $40 \mathrm{~kg} / \mathrm{m}^{2}$ or more, or between $35 \mathrm{~kg} / \mathrm{m}^{2}$ and $40 \mathrm{~kg} / \mathrm{m}^{2}$ with a significant disease (for example, type 2 diabetes or high blood pressure) that could be improved by weight loss

- All appropriate non-surgical measures have been tried for at least 6 months but have failed to achieve or maintain adequate, clinically beneficial weight loss

- The person has been receiving, or will receive, intensive management in a specialist obesity service

- The person is generally fit for anaesthesia and surgery

- The person commits to long-term follow-up

(National Collaborating Centre for Primary Care 2006)

comprehensive preoperative assessment of any psychological factors that may affect adherence to postoperative care requirements, including changes to diet. The guidelines emphasise that the patient should commit to long-term follow-up and that the multidisciplinary team should provide psychological support before and after surgery. However, at present there is no standard approach to psychological assessment.

Despite there being no evidence base to guide clinicians as to which patients should or should not have surgery, many services exclude up to $20 \%$ of referrals, frequently on psychological/ psychiatric grounds. A review of 81 US services identified considerable variance in what might be considered a contraindication. For example, 9\% excluded patients who had been in prison and $26 \%$ considered admission to a psychiatric hospital in the past year as representing no contraindication (Bauchowitz 2005).

Drawing on current evidence and the consensus of professionals working in bariatric teams, we provide an opinion and guidelines on the suitability of weight-loss surgery for people with mental illness.

\section{Types of bariatric surgery}

The three most commonly performed weight-loss operations offered to morbidly obese people are:

- laparoscopic adjustable gastric banding

- sleeve gastrectomy

- Roux-en-Y gastric bypass.

When considering which type of surgery to offer an individual, specialist bariatric services will take into account patient choice and which procedure is considered the most beneficial.

Gastric banding and sleeve gastrectomy appear to achieve weight loss primarily through restriction of stomach volume, whereas a gastric

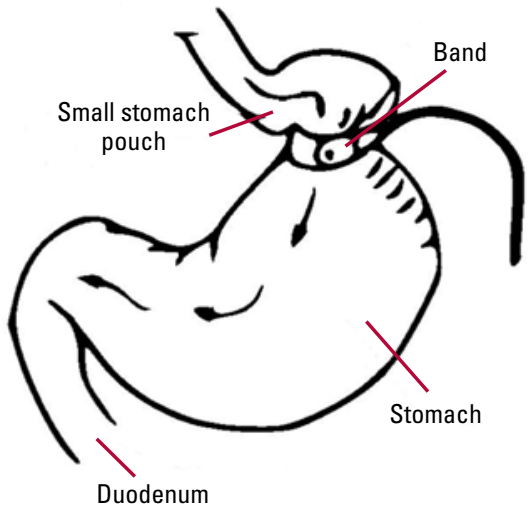

Adjustable gastric band.

bypass brings about both restriction and early postprandial release of satiating gut hormones such as PYY and GLP-1 (Bueter 2009).

\section{Laparoscopic adjustable gastric banding}

During gastric banding, an adjustable inflatable silicone band is placed around the proximal part of the stomach (Fig. 1). The band can be inflated and deflated according to clinical need. The amount of restriction is reduced if patients experience vomiting and dysphagia and can be increased if there is insufficient weight loss. The procedure results in weight loss of around 15$20 \%$ over 15 years and requires regular follow-up (Buchwald 2004). Complications such as slippage of the band, erosion of the stomach wall by the band and dilatation of the stomach pouch occur in up to $25 \%$ of patients. Removal of the band resolves such problems but, in most cases, there is subsequent weight regain to former levels of obesity. Some studies have found psychological factors such as disordered eating in association with these complications (Scholtz 2007).

\section{Sleeve gastrectomy}

Sleeve gastrectomy is a relatively new operation in which most of the stomach is removed to create a narrow conduit (Fig. 2). It is often offered to

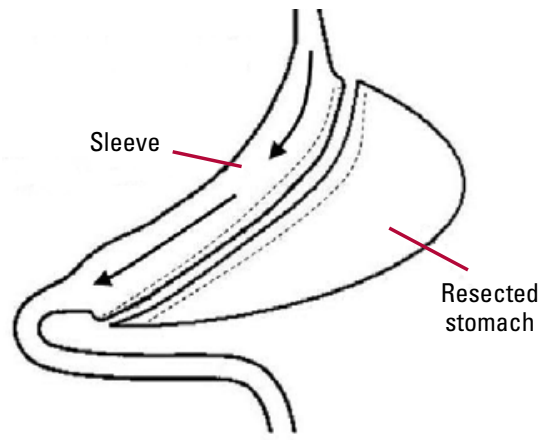


patients who have a BMI over $60 \mathrm{~kg} / \mathrm{m}^{2}$, as Rouxen- $Y$ gastric bypass (below) is technically harder to perform at a higher BMI. Originally part of a twostage procedure, with either conversion to gastric bypass or duodenal switch at a later stage, it may be suitable as a stand-alone intervention in some patients. Typical weight loss at 6 -year follow-up is about $20 \%$. Sleeve gastrectomy has similar effects on gut hormone release as gastric bypass surgery (Peterli 2009).

\section{Roux-en-Y gastric bypass}

Gastric bypass is, in our opinion, the gold standard of weight-loss surgery (Fig. 3) and brings about weight loss of around $30 \%$ at 15 years. It is associated with improvements in type 2 diabetes that appear to be weight-independent. Gastric bypass holds a higher surgical risk than the other two types of surgery described (mortality around $1 \mathrm{in} 300 \mathrm{v} .1 \mathrm{in} \mathrm{1000)}$ but this is comparable to the risk of elective laparoscopic cholecystectomy and complication rates are possibly lower in centres of excellence. The procedure is most effective for those with type 2 diabetes. The higher risks reflect short-term operative complications, including pulmonary embolism, anastomotic leaks, bleeding, wound infection and haemorrhage. Both sleeve gastrectomy and gastric bypass can lead to intestinal strictures in the longer term. Dumping syndrome (a complex neurohormonal disorder induced by eating concentrated sugars following gastric bypass) results in facial flushing, light-headedness, diarrhoea and fatigue. Gastric bypass causes malabsorption of some vitamins and micronutrients and is consequently associated with deficiencies in folate, $\mathrm{B}_{12}$, calcium, iron and other nutrients (DeMaria 2007).

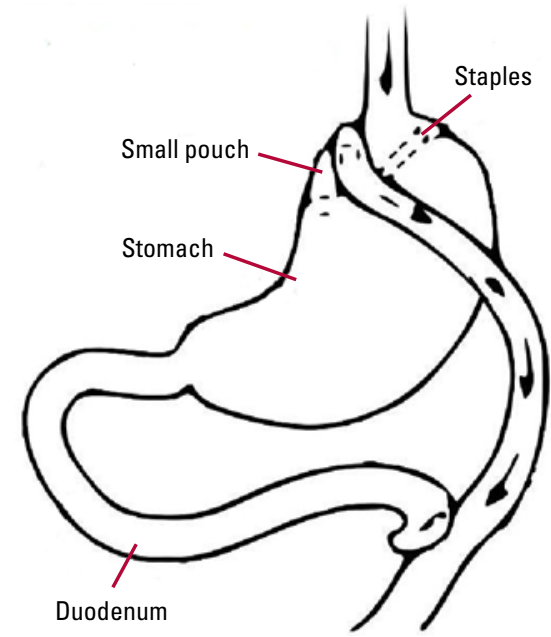

Roux-en- $Y$ gastric bypass.

Postoperative gastrointestinal complications are common after all three procedures, with nausea, dysphagia and vomiting occurring in up to $50 \%$ of patients. This can be caused by overeating or excessive restriction as a consequence of the procedure.

The relative benefits and complications of each procedure are outlined in Table 1 . There is much variance in surgical practice, and the procedures offered often reflect local experience and expertise. A Cochrane review of studies up to 2008 concluded that there was limited evidence on the comparative safety and effectiveness of these operations (Colquitt 2009). A detailed analysis of this area is beyond the scope of this article.

\section{Preoperative assessment}

The bariatric multidisciplinary team may include upper-gastrointestinal surgeons, physicians,

Which type of surgery is most suitable?

\begin{tabular}{|c|c|c|c|}
\hline Type of surgery & Advantages & Immediate complications & Later complications \\
\hline $\begin{array}{l}\text { Laparoscopic } \\
\text { adjustable gastric } \\
\text { banding }\end{array}$ & $\begin{array}{l}\text { Easily reversible if complications occur } \\
\text { Shorter in-patient stay } \\
\text { Lower peri-operative mortality }\end{array}$ & $\begin{array}{l}\text { Anaesthetic risks } \\
\text { Haemorrhage } \\
\text { Deep vein thrombosis/pulmonary embolism } \\
\text { Sepsis } \\
\text { Perforation of stomach } \\
\text { Infection at port site }\end{array}$ & $\begin{array}{l}\text { Band slippage } \\
\text { Erosion of stomach wall by gastric band } \\
\text { Rejection of band } \\
\text { Infection of band } \\
\text { Replacement due to leakage, fault or expiry }\end{array}$ \\
\hline Sleeve gastrectomy & Preferable in extreme obesity & $\begin{array}{l}\text { Anaesthetic risks } \\
\text { Haemorrhage } \\
\text { Deep vein thrombosis/pulmonary embolism } \\
\text { Sepsis } \\
\text { Leakage }\end{array}$ & $\begin{array}{l}\text { Gastroesophageal reflux and vomiting } \\
\text { Dumping syndrome } \\
\text { Weight regain } \\
\text { Stricture } \\
\text { Rarely: fistula }\end{array}$ \\
\hline $\begin{array}{l}\text { Roux-en-Ygastric } \\
\text { bypass }\end{array}$ & $\begin{array}{l}\text { More effective in those with type } 2 \text { diabetes } \\
\text { Greater weight loss } \\
\text { Most established and commonly performed } \\
\text { procedure } \\
\text { Shift in preference towards healthier foods }\end{array}$ & $\begin{array}{l}\text { Anaesthetic risks } \\
\text { Haemorrhage } \\
\text { Deep vein thrombosis/pulmonary embolism } \\
\text { Sepsis } \\
\text { Leakage }\end{array}$ & $\begin{array}{l}\text { Dumping syndrome } \\
\text { Increased risk of vitamin deficiency and } \\
\text { malnutrition } \\
\text { Small bowel herniation } \\
\text { Rarely: fistula, stricture }\end{array}$ \\
\hline
\end{tabular}


dieticians, anaesthetists, plastic surgeons, bariatric nurses and mental health professionals. Any decision to proceed with surgery will typically involve a risk-benefit analysis undertaken in a multidisciplinary meeting. Most centres require a surgical, anaesthetic and dietetic assessment to be carried out before surgery. The dietetic assessment will include an evaluation of nutritional adequacy. If hypothalamic and other endocrine causes of obesity are suspected or type 2 diabetes is poorly controlled, an endocrine assessment is done. The patient will have to make substantial post-operative changes to their diet and the amount and frequency of eating. Therefore, the assessment process places much emphasis on education and instilling appropriate expectations, helping patients to develop insight into their eating behaviour and to understand the behavioural changes necessary after surgery. Motivation for the operation will need to be assessed carefully. We believe that those seeking surgery to 'treat' underlying psychiatric disorders, as opposed to improving their mobility and physical health, pose a particular risk. Attendance at appointments and adherence to current treatment are considered by all members of the team, to assess commitment to change and longterm follow-up.

The NICE guidelines indicate that there is no evidence to support routine assessment by a mental health professional before bariatric surgery, although the assessment of psychological factors that might affect postoperative cooperation with treatment and follow-up and the need for psychological support before and after surgery are highlighted (National Collaborating Centre for Primary Care 2006). Mental health professionals are consequently inconsistently incorporated into bariatric surgical teams and the assessment of psychological factors may be undertaken by other members of the team. Nevertheless, many bariatric programmes have dedicated mental health professionals on the multidisciplinary team who may see all patients referred for surgery or a subgroup identified by screening. We recommend that all patients with a history of involvement with secondary mental health services should undergo a dedicated assessment by a mental health professional.

Even if a dedicated psychological evaluation and screening is included in preoperative assessment, there is considerable variation in practice (Pull 2010). Assessment will usually involve the domains outlined in Box 2 and often uses a structured assessment such as the Weight and Lifestyle Inventory (WALI; Wadden 2006).
BOX 2 Areas covered in routine psychosocial history

- Lifetime history of weight gain, including precipitating events

- History of weight-loss attempts

- Expectations from surgery

- Current eating habits and patterns

- Drug and alcohol use

- Past physical activity

- Past psychiatric history

- Current social circumstances

- Screening for current mental disorder, including depression and eating disorders

- Assessment of capacity

\section{Psychiatric assessment and preparation for surgery}

A psychiatric assessment to decide whether and when a patient with a mental disorder is eligible for bariatric surgery must cover a number of considerations. It should be seen as an opportunity to optimise mental health in preparation for surgery and to address and appropriately manage any identified risks. It should not be seen as a simple screen to exclude patients with mental health problems. The assessment will include a more detailed analysis of the domains outlined in Box 2, as well as a standard psychiatric history, mental state examination and cognitive assessment. Particular emphasis is placed on the chronology of weight change as an important clue to aetiology. For instance, dramatic weight gain after childhood sexual abuse might suggest an eating disorder, whereas weight gain after brain injury may suggest hypothalamic dysfunction and indicate the need for pituitary function tests.

\section{Patient's mental capacity and expectations}

It is important to establish whether a patient has the mental capacity to understand the nature of the operation, its risks and its benefits. It is also necessary to assess whether the individual has realistic expectations of the results of surgery. The patient should be aware that weight-loss surgery is considered successful if $20-30 \%$ of body weight is lost. The most drastic weight loss occurs 6-12 months after surgery, after which body weight plateaus and some weight regain is normal (Sjostrom 2004). Patients therefore may still be classified as obese after surgery, although their comorbid medical conditions and risks are 
significantly reduced. This degree of weight loss, although significant and sustained over time, does not always concur with the cosmetic or health aspirations of the patient.

\section{Postoperative dietary adherence}

It is important to identify any psychopathology that might affect adherence to the postoperative diet and acceptance of the need for life-long vitamins and follow-up. Weight-loss targets and food-diary monitoring can be used to assess motivational valence if there is doubt that the patient will be able to adhere to the rigorous postoperative dietary regimes.

All patients who have undergone bariatric surgery are at risk of malnutrition and vitamin deficiency. This is a particular risk with a gastric bypass, but is also seen in those who vomit after any restrictive procedure. Poor eating behaviour, food intolerance, vomiting and micronutrient malabsorption can lead to iron, vitamin $\mathrm{B}_{12}$, vitamin $\mathrm{D}$, calcium, folate and thiamine deficiencies (Aasheim 2009). In a US study of 1663 patients who underwent biliopancreatic diversion, 2 patients developed Wernicke-Korsakoff encephalopathy 3-5 months after surgery (Elliot 2003), and a systematic review found 80 case reports of Wernicke's encephalopathy after gastric bypass surgery (Aasheim 2008). These studies highlight the importance of adherence to multivitamin regimes to maintain nutrient levels.

\section{An assessment framework}

Using a system of red, amber and green, we suggest a framework for risk assessment that we have developed and incorporated into our practice
(Box 3). This gives an indication of psychological risk to be balanced against potential benefits or risks in other domains as assessed by other members of the multidisciplinary team, and facilitates communication with the surgical team. We recommend that those who fall into the red zone are unlikely to benefit from bariatric surgery in the immediate future and those in the amber zone warrant careful multidisciplinary team discussion of the risks and benefits and may need further interventions to improve eligibility, such as treatment of underlying eating disorders.

Patients with unstable psychotic illness, current alcohol or drug dependence, severe personality disorder and/or severe cognitive impairment are not suitable for weight-loss surgery as they are not able to adhere to the rigorous postoperative regimes (Norris 2007). There is a suggestion that those with a history of psychiatric admission have a poorer psychosocial outcome than those without (Valley 1987).

It is particularly important that patients with severe and enduring mental health problems are concordant with treatment and have realistic expectations of the outcome. Care should be taken to ensure that adequate psychosocial support is in place for these patients both at the time of surgery and after the first 6 months or so, when weight loss tends to reach a plateau. Those with a history of serious self-neglect and self-harm are probably not suitable for surgery unless circumstances have changed to a degree where the chances of future self-neglect are deemed low. Those with unpredictable behaviour associated with psychotic symptoms are unlikely to be able to follow the complicated postoperative dietary

BOX 3 A traffic-light system of preparedness for bariatric surgery

\begin{tabular}{lll}
\hline Red (not currently suitable for surgery) & Amber (possibly suitable, although deemed & Green (suitable for surgery) \\
- Unstable psychosis & to be at higher risk) & - Appropriate motivation \\
- Active substance misuse and alcohol & - Severe mental illness: mental state should & • Good understanding of procedure and outcomes \\
dependence & be stable for 12 months, with no hospital & - Appropriate expectations \\
- Severe/moderate learning disability & admissions or self-harm within that period & • Regular balanced diet \\
(intellectual disability) & - History of alcohol or substance misuse & - Insight into eating and causes of weight gain \\
- Dementia & - History of an eating disorder & - Proven adherence to treatment \\
- Severe personality disorder & - Mild learning disability (intellectual disability) & \\
- Self-harm in past 12 months & - Poor motivation & \\
- Active bulimia nervosa & - Unrealistic expectations & \\
- Current non-adherence to treatment & - Binge eating disorder & \\
& - Inadequate insight into eating behaviours & \\
& - Non-attendance \\
& - Poor adherence to previous advice and treatment &
\end{tabular}


changes needed. We therefore recommend that patients should not be considered for surgery unless over the previous 12 months they have had no relapses, characterised by unpredictable behaviour and functional impairment, and have adhered to treatment. We recommend that carers and a member of the local mental health team are consulted before surgery and agree a care plan to provide adequate practical support to the patient in the immediate postoperative period. In addition, increased frequency of contact, monitoring of medication or helping monitor for early signs of relapse are often recommended. These can help alleviate the stress of surgery and the loss of food as an emotional regulator.

\section{Complications after surgery}

In many ways, assessment is informed by the recognised complications of surgery (Box 4) that have been linked to mental health and identified through case reports and series. Many patients view surgery as a 'last chance', and although improvements in mental health are the norm (Shiri 2007), those who fail to lose weight, who are unable to tolerate the side-effects or who are otherwise dissatisfied with outcomes (particularly cosmetic) appear to be at particular risk. Suicide rates are higher in patients who have undergone gastric bypass surgery compared with similarly obese individuals (Adams 2007), and psychiatric admissions may be more frequent (Sarwer 2005). There are case reports of anorexia-type syndromes that have been dubbed 'post-surgical eating avoidance disorder' (Segal 2004). The evidence for the emergence of alternative addictive behaviours is less clear (Sogg 2007).

\section{Alcohol and drug dependence}

Patients with current alcohol or drug misuse should not have bariatric surgery. We recommend that patients with a history of substance misuse

BOX 4 Possible complications related to psychiatric disorder

- Relapse of psychiatric illness

- Suicide

- Amplification of self-induced vomiting

- Malnutrition

- Wernicke's encephalopathy

- Relapse, exacerbation or increase in drug or alcohol dependency

- Post-surgical eating avoidance disorder or other forms of disordered eating, such as binge eating demonstrate controlled use or abstinence for 12 months before surgery is considered. It is important to be aware that people with past or recent addictions may relapse or develop new addictions after surgery. It should be borne in mind that gastric bypass is likely to alter the metabolism of alcohol and enhance its effects (Hagedorn 2007). We recommend that those with a history of alcohol misuse do not receive malabsorptive procedures such as a gastric bypass, in view of the risk of Wernicke's encephalopathy in the event that they restart excessive drinking.

\section{Binge-eating disorder}

There is a high prevalence (10-50\%) of bingeeating disorder in patients referred for obesity surgery (Norris 2007). Ideally, active binge eating should be treated before surgery because there is a putative risk that the patient will fail to lose weight after surgery (Larsen 1990), although the evidence for this is inconsistent (Mitchell 2001). Bingeeating disorder can resolve following surgery, but some studies have reported anorexia and bulimia after surgery. Segal and colleagues (2004) have described purging, restriction, rapid weight loss and body-image distortion as part of post-surgical eating avoidance disorder.

\section{Childhood trauma}

Patients seeking weight-loss surgery report high rates of childhood adversity (69\%; Grilo 2005) and sexual abuse (17\%; Gustafson 2004). It is important to consider how patients have been affected by past events, as we believe that this can affect their insight into their eating behaviours. Many patients describe 'comfort eating' and obesity as a defence mechanism in response to past abuse. Alternative coping behaviours must therefore be discussed with them, and some will benefit from psychotherapy before and after surgery.

\section{Personality disorders}

The chaotic lifestyle seen in people with personality disorders may undermine cooperation with dietary change and follow-up. It is vital to ensure that patients can demonstrate enduring changes to maladaptive behaviours, including selfharm and other destructive behaviours. In these circumstances, we would consider that a period of stability of at least 12 months is needed.

\section{Effects of bariatric surgery on psychotropic medication}

The pharmacokinetics of psychotropics following weight-loss surgery remains poorly understood and there is a scant literature. Gastric banding 


\section{MCO answers}

1 e 2 e 3 b 4 b $5 d$ may increase the time that drugs remain in the proximal part of the stomach, although there has been no systematic evaluation of psychotropic pharmacokinetics after the procedure. Most change is seen following more invasive procedures, such as gastric bypass. This can reflect altered pH and drug solubility, bypassing major portions of the upper gastrointestinal tract and reducing the surface area for absorption. In practice, pharmacists usually recommend changing from enteric-coated and delayed-release formulations.

Changes to absorption have been inferred from assessment of changes in dissolution of common psychiatric drugs following gastric bypass in a laboratory setting (Table 2), although dissolution alone does not predict therapeutic efficiency (Seaman 2005).

A Canadian review (Taylor 2009) has suggested that some medications, especially lamotrigine, olanzapine, quetiapine and extended-release antidepressants, may be poorly absorbed post-bypass and should be regularly monitored. Lithium presents particular risks of toxicity (Tripp 2011) owing to its narrow therapeutic window, and levels should be closely monitored after bariatric surgery.

In practice, we have found that in most patients psychotropic medication does not need to be altered after surgery, but that caution should be exercised by monitoring therapeutic response.

\section{Conclusions}

General psychiatrists are likely to be presented with requests for opinions on the suitability of their patients for bariatric surgery. Many obese people with mental illness will benefit from weightloss surgery, but careful preoperative assessment and selection are required. It is essential that this process does not discriminate against this group or delay access to surgery. Postoperative monitoring of patients' medical and psychological states is important.

TABLE 2 Predicted impact of Roux-en- $Y$ gastric bypass on pharmacokinetics of psychotropic drugs

\begin{tabular}{|lll|}
\hline & Absorption following bypass \\
\hline Reduced & Increased & No difference \\
\hline Amitriptyline & Bupropion & Citalopram \\
Clozapine & Lithium & Haloperidol \\
Fluoxetine & (significant & Venlafaxine \\
Olanzapine & increase) & \\
Paroxetine & & \\
Quetiapine & & \\
Risperidone & & \\
Sertraline & & \\
Ziprasidone & & \\
\hline
\end{tabular}

Source: Seaman 2005.

\section{References}

Aasheim ET (2008) Wernicke encephalopathy after bariatric surgery: a systematic review. Annals of Surgery 248: 714-20.

Aasheim ET, Björkman S, Søvik TT, et al (2009) Vitamin status after bariatric surgery: a randomized study of gastric bypass and duodenal switch. American Journal of Clinical Nutrition 90: 15-22.

Adams TD, Gress RE, Smith SC, et al (2007) Long-term mortality after gastric bypass surgery. New England Journal of Medicine 357: 753-61.

Bauchowitz AU, Gonder-Frederick LA, Olbrisch ME, et al (2005) Psychosocial evaluation of bariatric surgery candidates: a survey of present practices. Psychosomatic Medicine 67: 825-32.

Buchwald H, Avidor Y, Braunwald E, et al (2004) Bariatric surgery: A systematic review and meta-analysis. Journal of the American Medical Association 292: 1724-37

Bueter M, Ashrafian H, Le Roux CW (2009) Mechanisms of weight loss after gastric bypass and gastric banding. Obesity Facts 2: 325-31.

Colquitt JL, Picit J, Loveman E, et al (2009) Surgery for obesity. Cochrane Database of Systematic Reviews, issue 2: CD003641.

DeMaria EJ (2007) Bariatric surgery for morbid obesity. New England Journal of Medicine 356: 2176-83

Devlin MJ, Yanouski SZ, Wilson GT (2000) Obesity: what mental health professionals need to know. American Journal of Psychiatry 157: 854-66.

Elliot K (2003) Nutritional considerations after bariatric surgery. Critical Care Nursing Quarterly 26: 133-8.

Friedman MA, Brownell KD (1995) Psychological correlates of obesity: moving to the next research generation. Psychological Bulletin 117: 3-20.

Grilo CM, Masheb RM, Brody M (2005) Childhood maltreatment in extremely obese male and female bariatric surgery candidates. Obesity Research 13: 123-30.

Gustafson TB, Sarwer DB (2004) Childhood sexual abuse and obesity. Obesity Reviews 5: 129-35

Hagedorn JC, Encarnacion B, Brat GA, et al (2007) Does gastric bypass alter alcohol metabolism? Surgery for Obesity and Related Diseases. 3: 543-8.

Herpertz S, Kielmann R, Wolf AM, et al (2004) Do psychosocial variables predict weight loss or mental health after obesity surgery? A systematic review. Obesity Research 12: 1554-69.

Kalarchian MA, Marcus MD, Levine MD, et al (2007) Psychiatric disorders among bariatric surgery candidates: relationship to obesity and functional health status. American Journal of Psychiatry 164: 328-34.

John U, Meyer C, Hans-Jurgen R, et al (2005) Relationships of psychiatric disorders with overweight and obesity in an adult general population. Obesity Research 13: 101-9.

Larsen F (1990) Psychosocial function before and after gastric banding surgery for morbid obesity. A prospective study. Acta Psychiatrica Scandinavica Supplementum 359: 1-57.

McElroy SL (2009) Obesity in patients with severe mental illness: Overview and management. Journal of Clinical Psychiatry 70: 12-21.

Mitchell JE, Lancaster KL, Burgard MA, et al (2001) Long-term follow-up of patients' status after gastric bypass. Obesity Surgery 11: 464-8.

National Collaborating Centre for Primary Care (2006) Obesity: Guidance on the Prevention, Identification. Assessment and Management of Overweight and Obesity in Adults and Children (CG 43). NICE.

Norris $L$ (2007) Psychiatric issues in bariatric surgery. Psychiatric Clinics of North America 30: 717-38.

Peterli R, Wölnerhanssen B, Peters T, et al (2009) Improvement in glucose metabolism after bariatric surgery: comparison of laparoscopic Rouxen-Y gastric bypass and laparoscopic sleeve gastrectomy. A prospective randomized trial. Annals of Surgery 250: 234-41.

Pull CB (2010) Current psychological assessment practices in obesity surgery programs: what to assess and why. Current Opinion in Psychiatry. 23: $30-6$

Sarwer DB, Wadden TA, Fabricatore AN (2005) Psychosocial and behavioral aspects of bariatric surgery. Obesity Research 13: 639-48. 
Scholtz S, Bidlake L, Morgan J, et al (2007) Long-term outcomes following laparoscopic adjustable gastric banding: postoperative psychological sequelae predict outcome at 5-year follow-up. Obesity Surgery 17: $1220-5$.

Seaman JS, Bowers SP, Dixon P, et al (2005) Dissolution of common psychiatric treatment in a Roux-en-Y gastric bypass model. Psychosomatics 46 : $250-3$.

Segal A, Kussunoki DK, Larino MA (2004) Post-surgical refusal to eat: anorexia nervosa, bulimia nervosa, or a new eating disorder? A case series. Obesity Surgery 14: 353-60.

Shiri S, Gurevich T, Feintuch U, et al (2007) Positive psychological impact of bariatric surgery. Obesity Surgery 17: 663-8.

Sims A (1987) Why the excess mortality from psychiatric illness? BMJ 294: 986-7.

Sjostrom L, Lindrosos AK, Peltonen L, et al (2004) Lifestyle, diabetes, and cardiovascular risk factors 10 years after bariatric surgery. New England Journal of Medicine 351: 2683-93.
Sogg S (2007) Alcohol misuse after bariatric surgery: epiphenomenon or 'Oprah' phenomenon? Surgery for Obesity and Related Diseases 3. $366-8$.

Stunkard A, Wadden TA (2000) Obesity. In New Oxford Textbook of Psychiatry (eds MG Gelder, J Lopez-lbor Jr, NC Andreason): 867-74. Oxford University Press.

Taylor VH, Misra M (2009) Psychopharmacology for the clinician. Journal of Psychiatry \& Neuroscience 34: E3-4.

Tripp AC (2011) Lithium toxicity after Roux-en-Y bypass surgery. Journal of Clinical Psychopharmacology 31: 261-2.

Valley V, Grace DM (1987) Psychosocial risk factors in gastric surgery for obesity: identifying guidelines for screening. International Journal of Obesity 11: 105-13.

Wadden TA, Foster GD (2006) The Weight and Lifestyle Inventory (WALI). Obesity 14: 99-118.

\section{MCQs}

Select the single best option for each question stem

1 Following gastric banding, it is considered realistic for patients to lose:

a $100 \%$ of their excess weight

b $50-70 \%$ of their total body weight

c $20-30 \%$ of their excess weight

d $100 \%$ of their total body weight

e $20 \%$ of their total body weight.

\section{Following gastric bypass, there is} increased absorption of:

a fluoxetine

b sertraline

c clozapine

d olanzapine

e none of the above.
3 It is an absolute contraindication to Roux-en- $Y$ bypass if a patient has:

a severe mental illness

b current alcohol dependence

c mild intellectual difficulties

d history of an eating disorder

e unrealistic expectations.

4 Complications/side-effects of a gastric band procedure do not include:

a dysphagia

b dumping syndrome

c vomiting

$\mathrm{d}$ haemorrhage

e erosion of the stomach wall.
5 The NICE criteria for bariatric surgery recommend that the patient has:

a a BMI greater than 30 with comorbid obesityrelated illness

b a BMI greater than 35 without comorbid obesity-related illness

c undergone a successful trial of anti-obesity medication

d the ability to commit to long-term follow-up

e achieved a $5 \%$ weight loss using other methods. 